\title{
Reliability of Measuring Morphology of the Paediatric Foot Using the Artec Eva Hand Held Scanner
}

\author{
Matyas VARGA ${ }^{1 *}$, Stewart C. MORRISON ${ }^{1}$, Carina PRICE ${ }^{2}$ \\ ${ }^{1}$ School of Health Sciences, University of Brighton, Eastbourne, UK; \\ ${ }^{2}$ School of Health and Society, University of Salford, Salford, UK
}

https://doi.org/10.15221/19.236

\begin{abstract}
The growth and development of the paediatric foot throughout childhood is poorly understood. To inform theory that underpins clinical practice, there is a clear need to revisit our understanding of how the foot develops. Hand-held 3-D scanners provide portability and allow researchers to collect data about foot development in the children's natural environment. However, there are methodological challenges to consider: scanning the plantar surface in a static weight-bearing position, the children's ability to remain static for the duration of the scanning and software capabilities. The aim of this study was to determine the reliability of using a hand-held scanner to capture children's foot shape and size.

For this study, 15 children aged two years (Group 1: $n=5$ ), five years (Group 2: $n=5$ ) and seven years (Group 3: $n=5$ ) were recruited. Children stood barefoot in a comfortable bipedal stance, on a Perspex platform of $550 \mathrm{~mm}$ height. Their feet were scanned three times, including the plantar surface through the platform, using the Artec Eva (Artec Group, Luxembourg, Luxembourg) hand held scanner. Postprocessing of the scans was performed in Artec Studio 12 (Artec Group, Luxembourg, Luxembourg). Data processing and statistical analysis of 3D data were performed in Matlab R2018a (The Mathworks, Natuck, USA), while linear measures were calculated in Foot3D (INESCOP, Elda, Spain). To assess reliability, root mean square error (RMSE) of 11 linear measurements, mesh deviations (Euclidean distances) of the 3D coordinates of corresponding vertices (after rigid registration of the meshes) [5] and RMSE for shape-index (SI) and curvedness (CU) [6] were calculated.

Results showed good reliability for eight linear measures with an average RMSE of $1.14 \mathrm{~mm}$ across groups and all measures (RMSE range: $0.19 \mathrm{~mm}-3.73 \mathrm{~mm}$ ). Three measures exceeded a RMSE of $2 \mathrm{~mm}$, two of which were from Group 1. Mesh deviation results showed good reliability in the older children (Group 2: deviations under 0.5mm: $73.03 \%$, under $1 \mathrm{~mm}: 94.12 \%$, Group 3: deviations under $0.5 \mathrm{~mm}: 68.82 \%$, under $1 \mathrm{~mm}: 96.20 \%$ ), but not in the youngest group (deviations under $0.5 \mathrm{~mm}: 53.19 \%$, under $1 \mathrm{~mm}: 85.83 \%$ ). The heat maps of mesh deviations across the foot surface, indicate increasing mesh deviations in the toe and ankle area from Group 3 to Group 2, while Group 1 also had higher than $1 \mathrm{~mm}$ deviations on the lateral and dorsal surface of the foot. Root mean square error for curvedness and shape-index for the 3 scans of the same foot decreased with increasing age, but in general indicated good reliability.

The results of this study demonstrated that the hand-held scanner was reliable for capturing children's 3D foot shape, however there were methodological issues in the youngest group. In Group 1, the mesh deviation results demonstrated lower reliability in four distinct areas (toes, lateral and dorsal surface and ankle). The higher mesh deviations were a result of these children being unable to stand still for the duration of the scan and having a more variable stance on the platform between scans. The fact that the RMSE of two linear measures exceeded $2 \mathrm{~mm}$ in the youngest group also supported this proposal. Future studies employing hand held 3D scanners should consider these results and handle 3D scanning data of two years old children with caution.
\end{abstract}

Keywords: foot scanning, children, reliability, 3D foot shape, shape-index

\section{Introduction}

Understanding the trajectory of foot shape across childhood is important for informing footwear design, orthotic research and advancing approaches to clinical practice. This data can provide reference values which characterise the development of the foot shape [1-4], diagnosis of foot pathologies [5-8], evaluation of post-surgical outcomes [9] and information on foot shape and variation which could aid shoe design [10-13]. A variety of methods are used to acquire foot measurements, with manual and foot print measurements being the most commonly used in clinical practice, while step-in 3D foot scanning is more commonly used in modern approaches to orthotics design, customized foot wear fitting and research [4, 6, 9, 14-21]. As hand-held scanners have also become commercially available, they provided a portable and less expensive methodological alternative to step-in scanners to quantify 3D foot shape. 
Approaches to measure the foot can include $2 \mathrm{D}$ linear measures (e.g. foot length, navicular height) and 3D shape descriptors (e.g. shape-index, curvedness [31, 32]) Shape descriptors may complement linear measures and help to describe subtle changes in 3D shape where linear measures cannot capture the multi-planar motion and complexity of the foot $[8,22]$. These measures can provide a map of convex, concave and hyperbolic areas [23], and define the magnitude of surface curvature at each point on the foot. Shape index is independent of scale whereas curvedness is not which provides two different types of 3D measurement, both of which could be useful to characterise developmental changes in foot shape.

When using hand held or step-in 3D foot scanning for capturing 2D linear or 3D shape data of children's feet, reliability is key for high standard research. Children's feet are highly varied in size: foot length: $130.7 \mathrm{~mm}$ at the age of one (Muller et al., 2012a), $184.4 \mathrm{~mm}$ at the age of 6 and 254.9 at the age of 18 (Waseda et al., 2014) and shape. In addition to size and shape differences, the fatty tissue typically present in the younger age groups, makes palpating or detecting anatomical landmarks more difficult and these age groups are also more prone to movement during scanning than adults. Studies that examined the reliability of $3 D$ scanning for $2 D$ foot measurement in children $[10,20]$ used the Pedus 3D step-in scanner (Pedus, Human Solutions Inc., Germany). The authors reported root mean square error (RMSE) [24] for 5 [10] and 12 [20] 2D measures in children aged two to 14 years of age. This ranged between $0.5 \mathrm{~mm}$ and $2 \mathrm{~mm}$ [20] and between 0.5 and $1 \mathrm{~mm}$ [10] which suggests high reliability comparable to manual clinical methods. Hand-held scanners, including the Artec Eva, have been used in different research fields [25-28] but their reliability has not been addressed in children's foot measurement [26, 28-32]. As a consequence, further work is needed to understand the reliability of the measurement of children's feet. The aim of this study was therefore to test the reliability of capturing linear anthropometric and 3D shape measures of the foot in children using the Artec Eva hand held scanner.

\section{Methods}

\subsection{Ethical approval}

Ethical approval was obtained from the School of Health Sciences Research Ethics Committee at the University of Brighton. Informed consent was obtained from the parents of all participants.

\subsection{Participants}

Fifteen children aged two, five and seven years of age were recruited. The children were put into three age groups: Group 1: two (3 males and 2 females), Group 2: five (3 females and 2 males) and Group 3: seven ( 3 females and 2 males) years old. The exclusion criteria were: skin disorders affecting the foot such as eczema, psoriasis or any skin abrasions; and suffering from epilepsy or light sensitive conditions.

\subsection{Data Capture}

Scanning of the feet was undertaken within the community, using the Artec Eva scanner.

Participants stood barefoot in a bipedal stance and although both feet were scanned, only their right feet were considered for analysis to ensure statistical independence within the samples [33]. To allow the scanning of the plantar surface a transparent Perspex platform (certified up to $150 \mathrm{~kg}$ bodyweight) and a custom built stand of $550 \mathrm{~mm}$ height were used (Figure 1.).

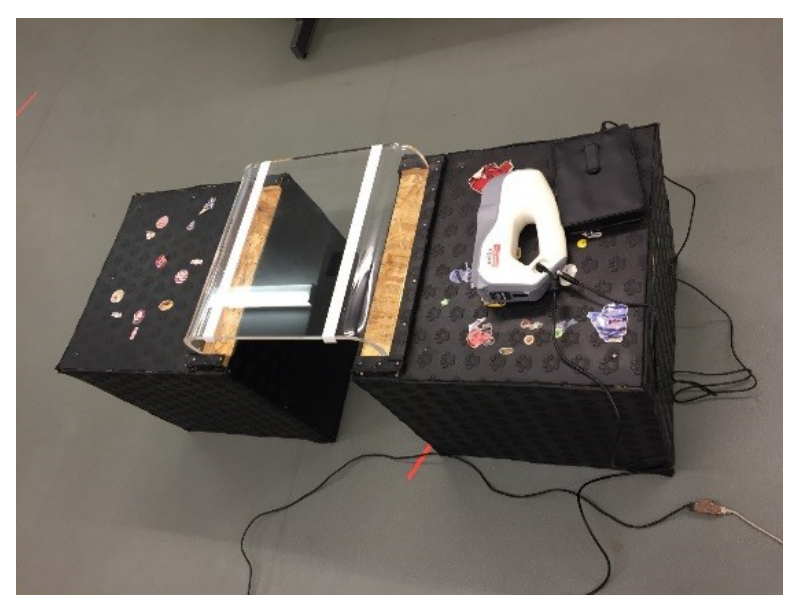

Figure 1: The Perspex platform on the custom built stand and the Artec Eva hand held scanner. 


\subsection{Post-processing}

Artec Studio software (Artec Studio 12, Artec 3D) was utilized for post-processing of the scans to create a full 3D model of each foot. Once all models were created, the three scans of the same foot were simplified (number of vertices reduced) to the lowest number of vertices of the three models, to allow vertex-to-vertex comparison and the calculation of mesh deviations. All models also underwent isotropic remeshing which aids further vertex-to-vertex comparisons between models. The three models of the same foot were automatically aligned and then globally registered in Artec Studio 12. The three models were then cut above the medial malleolus while being overlaid, to ensure they were cut at the same level, so both the medial and lateral ankle were still part of the model. This was needed for the calculation of linear measurements in the Foot3D software. The models were then exported as stereolithography (stl) files into Matlab and Foot 3D.

\subsubsection{Linear anthropometric measures}

The measurement of linear anthropometric parameters (Table 1.) was performed automatically in Foot3D software (INESCOP, Spain). The automated marker recognition and placement were checked and manually adjusted when needed.

Table 1: The description and definition of the linear measures calculated by Foot3D.

\begin{tabular}{|c|l|}
\hline Linear measure & \multicolumn{1}{|c|}{ Description } \\
\hline Foot length & $\begin{array}{l}\text { Distance between most posterior point of the heel and the end of the } \\
\text { longest toe, projected onto the longitudinal axes }\end{array}$ \\
\hline Forefoot Width & Distance across the widest points of the forefoot. \\
\hline $\begin{array}{c}\text { Metatarsal head } \\
1 \text { length }\end{array}$ & $\begin{array}{l}\text { Distance between the rearmost point of the foot and the first } \\
\text { Metatarsal head. }\end{array}$ \\
\hline $\begin{array}{c}\text { Metatarsal head } \\
5 \text { length }\end{array}$ & $\begin{array}{l}\text { Distance between the rearmost point of the foot and the fifth } \\
\text { Metatarsal head. }\end{array}$ \\
\hline Ball width & Distance between points metatarsal head one and five. \\
\hline Ball height & Height of ball point. \\
\hline Heel width & $\begin{array}{l}\text { Distance obtained between the outermost points to intersect a plane } \\
\text { perpendicular to the foot axis away 15\% of foot length and 1 cm high. }\end{array}$ \\
\hline Instep height & Distance between the point of the instep and the ground plane. \\
\hline $\begin{array}{c}\text { Medial } \\
\text { malleolus height }\end{array}$ & $\begin{array}{l}\text { The distance between the supporting surface and the most medial point } \\
\text { of the medial malleolus. }\end{array}$ \\
\hline $\begin{array}{c}\text { Lateral } \\
\text { malleolus height }\end{array}$ & $\begin{array}{l}\text { The distance between the supporting surface and the most lateral point } \\
\text { of the lateral malleolus. }\end{array}$ \\
\hline Ankle width & $\begin{array}{l}\text { The distance between the most medial point of the medial malleolus and } \\
\text { the most lateral point of the lateral malleolus. }\end{array}$ \\
\hline
\end{tabular}

\subsubsection{D shape descriptors}

Once stl files of foot models were imported, $\mathrm{X}, \mathrm{Y}$ and $\mathrm{Z}$ axes and the origin were defined, as the corner representing the most posterior, lateral and inferior point of the foot. Once in the same coordinate system, the three models of the same foot were registered using a rigid, iterative closest point algorithm based registration function of point clouds in Matlab [34,35]. After registering the three models, a triangulation was performed to achieve higher accuracy in identifying nearest neighbours and to be able to calculate curvature. To avoid high inconsistency in the data, only the points under the medial malleolus were considered for $3 \mathrm{D}$ shape analysis. These were extracted using a custom written algorithm. Principal (minimum and maximum) and Gaussian-curvature were calculated using a custom written script by Gabriel Peyre [36], based on Cohen-Steiner and Morvan [37] and Alliez, Cohen-Steiner [38]. Using the above measures shape-index and curvedness were calculated based on the equation used in Koenderink and van Doorn [39] in a custom written code.

\subsection{Statistical analysis}

\subsubsection{Linear Measures}

Absolute root mean squared error (RMSE) [40] was calculated to provide information on the absolute difference between the repeated measures. 


\subsubsection{D shape descriptors}

To evaluate the reliability of the scanning method, mesh deviations (or surface-to-surface distances) were calculated between the three measurements of the same foot for all participants, using Euclideandistances between corresponding vertices. Cumulative statistics were calculated to identify the percentage of deviations under $0.5 \mathrm{~mm}$ and $1 \mathrm{~mm}$, which quantifies agreement between meshes [41]. To quantify the absolute reliability of measuring 3D shape the RMSE for shape-index and curvedness at the corresponding vertices of the foot scans, was calculated for the three scans of the same foot [40].

\section{Results}

\subsection{The reliability of the linear measures}

Data for all linear measures are presented in Table 2. The average absolute RMSE for all measures across groups did not exceed $2 \mathrm{~mm}$ (mean=1.14 $\mathrm{mm}$ ), and the maximum RMSE was found in metatarsal head one (MTH1) length measurement $-3.73 \mathrm{~mm}$ in Group 1. Across groups the average RMSE of MTH1 and metatarsal head five (MTH5) exceeded $2 \mathrm{~mm}$. When investigating the RMSEs in the groups, two measures (MTH1 and MTH5) RMSE exceeded $2 \mathrm{~mm}$ in Group 1, and MTH1 RMSE also exceeded $2 \mathrm{~mm}$ in Group 3. For eight out of the 11 linear measures the highest RMSE was found in Group 1. Ball width and heel width RMSE was the highest in Group 3; and medial malleolus height RMSE was the highest in Group 2.

Table 2: Mean and root mean square error (RMSE) for each linear measure by group. Abbreviations: MTH1: metatarsal head 1, MTH5: metatarsal head 5, M. mall.: medial malleolus, L. mall.: lateral malleolus

\begin{tabular}{|c|c|c|c|c|c|c|c|}
\hline & \multicolumn{2}{|c|}{ Group 1} & \multicolumn{2}{|c|}{ Group 2} & \multicolumn{2}{|c|}{ Group 3} & \multirow{2}{*}{$\begin{array}{c}\text { Across } \\
\text { groups } \\
\begin{array}{c}\text { Mean } R M S E \\
(S D)(m m)\end{array}\end{array}$} \\
\hline & $\begin{array}{c}\text { Mean } \\
(S D) \\
(\mathrm{mm})\end{array}$ & $\begin{array}{c}\text { RMSE } \\
(\mathrm{mm})\end{array}$ & $\begin{array}{c}\text { Mean } \\
(S D) \\
(\mathrm{mm})\end{array}$ & $\begin{array}{c}\text { RMSE } \\
(\mathrm{mm})\end{array}$ & $\begin{array}{c}\text { Mean } \\
(S D) \\
(\mathrm{mm})\end{array}$ & $\begin{array}{c}\text { RMSE } \\
(\mathrm{mm})\end{array}$ & \\
\hline Foot length & $\begin{array}{c}154.63 \\
(4.82) \\
\end{array}$ & 0.9 & $\begin{array}{c}173.48 \\
(5.05) \\
\end{array}$ & 0.64 & $\begin{array}{c}203.9 \\
(17.03)\end{array}$ & 0.58 & $0.71(0.17)$ \\
\hline Foot Width & $\begin{array}{l}63.97 \\
(3.43)\end{array}$ & 0.5 & $\begin{array}{l}70.13 \\
(5.18)\end{array}$ & 0.47 & $\begin{array}{l}74.21 \\
(8.86)\end{array}$ & 0.49 & $0.49(0.02)$ \\
\hline MTH1 length & $\begin{array}{c}111.72 \\
(5.85)\end{array}$ & 3.73 & $\begin{array}{c}126.93 \\
(3.52)\end{array}$ & 1.13 & $\begin{array}{l}145.88 \\
(16.32)\end{array}$ & 3.29 & $2.72(1.39)$ \\
\hline MTH5 length & $\begin{array}{l}98.36 \\
(7.61)\end{array}$ & 2.47 & $\begin{array}{c}110.51 \\
(2.42)\end{array}$ & 1.91 & $\begin{array}{c}130.34 \\
(15.49)\end{array}$ & 1.84 & $2.07(0.35)$ \\
\hline Ball width & $\begin{array}{l}65.66 \\
(3.74)\end{array}$ & 0.69 & $\begin{array}{l}72.12 \\
(5.22)\end{array}$ & 0.59 & $\begin{array}{l}78.17 \\
(8.67)\end{array}$ & 1.4 & $0.89(0.44)$ \\
\hline Ball height & $\begin{array}{l}28.89 \\
(1.31) \\
\end{array}$ & 1.15 & $\begin{array}{l}29.92 \\
(1.66)\end{array}$ & 0.78 & $\begin{array}{l}32.91 \\
(4.85) \\
\end{array}$ & 0.71 & $0.88(0.24)$ \\
\hline Heel width & $\begin{array}{l}42.16 \\
(1.46)\end{array}$ & 0.48 & $\begin{array}{l}44.99 \\
(3.12)\end{array}$ & 0.46 & $\begin{array}{l}49.84 \\
(3.77)\end{array}$ & 0.53 & $0.49(0.04)$ \\
\hline Instep height & $\begin{array}{l}52.17 \\
(1.02) \\
\end{array}$ & 1.39 & $\begin{array}{l}58.29 \\
(1.62) \\
\end{array}$ & 0.68 & $\begin{array}{c}61.4 \\
(3.73) \\
\end{array}$ & 0.76 & $0.94(0.39)$ \\
\hline M. mall. height & $\begin{array}{l}51.02 \\
(1.16)\end{array}$ & 0.72 & $\begin{array}{l}57.95 \\
(2.29)\end{array}$ & 1.88 & $\begin{array}{l}60.73 \\
(6.05)\end{array}$ & 1.59 & $1.40(0.60)$ \\
\hline L. mall. height & $\begin{array}{l}43.99 \\
(2.29)\end{array}$ & 1.79 & $\begin{array}{l}46.34 \\
(2.30)\end{array}$ & 0.95 & $\begin{array}{l}57.34 \\
(7.86)\end{array}$ & 0.98 & $1.24(0.48)$ \\
\hline Ankle width & $\begin{array}{l}50.84 \\
(1.16)\end{array}$ & 0.72 & $\begin{array}{l}56.46 \\
(1.88)\end{array}$ & 0.7 & $\begin{array}{l}63.33 \\
(8.66)\end{array}$ & 0.69 & $0.70(0.02)$ \\
\hline MEAN (SD) & & $\begin{array}{c}1.32 \\
(1.00)\end{array}$ & & $\begin{array}{c}0.93 \\
(0.52)\end{array}$ & & $\begin{array}{c}1.17 \\
(0.84)\end{array}$ & $1.14(0.2)$ \\
\hline
\end{tabular}




\subsection{Reliability of 3D shape descriptors}

The results of the mesh deviation calculations can be seen in Table 3. The mean percentage of mesh deviations across participants under $0.5 \mathrm{~mm}$ was $63.42 \%(\mathrm{SD}=8.65)$ and under $1 \mathrm{~mm}$ was $91.22 \%$. $(S T D=5.60)$. The lowest reliability values were found in Group 1 both for under 0.5 and $1 \mathrm{~mm}$ and there was an increase in reliability with increasing age except for the deviations under $0.5 \mathrm{~mm}$ where Group 2 had a higher result (73.03\%) compared to Group 1 (68.82\%).

Table 3: Percentage of mesh deviation under 0.5 and $1 \mathrm{~mm}$ for each participant within each group.

\begin{tabular}{|c|c|c|c|c|c|c|}
\hline \multicolumn{7}{|c|}{ Group 1} \\
\hline & $\begin{array}{c}\text { Participant } \\
1\end{array}$ & $\begin{array}{c}\text { Participant } \\
2\end{array}$ & $\begin{array}{c}\text { Participant } \\
3\end{array}$ & $\begin{array}{c}\text { Participant } \\
4\end{array}$ & $\begin{array}{c}\text { Participant } \\
5\end{array}$ & $\begin{array}{l}\text { MEAN } \\
\text { (STD) }\end{array}$ \\
\hline $\begin{array}{l}\text { \% of mesh } \\
\text { deviations } \\
\text { under } 0.5 \mathrm{~mm}\end{array}$ & $54.72 \%$ & $71.56 \%$ & $35.33 \%$ & $38.28 \%$ & $66.09 \%$ & $\begin{array}{l}53.19 \% \\
(16.18)\end{array}$ \\
\hline $\begin{array}{l}\% \text { of mesh } \\
\text { deviations } \\
\text { under } 1 \mathrm{~mm}\end{array}$ & $93.15 \%$ & $96.16 \%$ & $69.61 \%$ & $67.92 \%$ & $97.34 \%$ & $\begin{array}{c}85.83 \% \\
(14.76)\end{array}$ \\
\hline \multicolumn{7}{|c|}{ Group 2} \\
\hline Participants & $\begin{array}{c}\text { Participant } \\
1\end{array}$ & $\begin{array}{c}\text { Participant } \\
2\end{array}$ & $\begin{array}{c}\text { Participant } \\
3\end{array}$ & $\begin{array}{c}\text { Participant } \\
4\end{array}$ & $\begin{array}{c}\text { Participant } \\
5\end{array}$ & $\begin{array}{l}\text { MEAN } \\
\text { (STD) }\end{array}$ \\
\hline $\begin{array}{l}\text { \% of mesh } \\
\text { deviations } \\
\text { under } 0.5 \mathrm{~mm}\end{array}$ & $93.81 \%$ & $37.94 \%$ & $77.84 \%$ & $72.37 \%$ & $83.20 \%$ & $\begin{array}{l}73.03 \% \\
(21.16)\end{array}$ \\
\hline $\begin{array}{l}\text { \% of mesh } \\
\text { deviations } \\
\text { under } 1 \mathrm{~mm}\end{array}$ & $99.49 \%$ & $80.13 \%$ & $95.71 \%$ & $96.48 \%$ & $98.77 \%$ & $\begin{array}{c}94.12 \% \\
(7.97)\end{array}$ \\
\hline \multicolumn{7}{|c|}{ Group 3} \\
\hline & $\begin{array}{c}\text { Participant } \\
1\end{array}$ & $\begin{array}{c}\text { Participant } \\
2\end{array}$ & $\begin{array}{c}\text { Participant } \\
3\end{array}$ & $\begin{array}{c}\text { Participant } \\
4\end{array}$ & $\begin{array}{c}\text { Participant } \\
5\end{array}$ & $\begin{array}{l}\text { MEAN } \\
\text { (STD) }\end{array}$ \\
\hline $\begin{array}{l}\text { \% of mesh } \\
\text { deviations } \\
\text { under } 0.5 \mathrm{~mm}\end{array}$ & $61.10 \%$ & $60.98 \%$ & $68.09 \%$ & $88.03 \%$ & $76.24 \%$ & $\begin{array}{l}68.82 \% \\
(11.47)\end{array}$ \\
\hline $\begin{array}{l}\text { \% of mesh } \\
\text { deviations } \\
\text { under } 1 \mathrm{~mm}\end{array}$ & $94.04 \%$ & $93.95 \%$ & $98.83 \%$ & $99.98 \%$ & $96.49 \%$ & $\begin{array}{c}96.20 \% \\
(3.49)\end{array}$ \\
\hline
\end{tabular}

Figure 5 demonstrates the mesh deviations for one participant from each age group and are included for illustrative purposes. The percentage of deviations between 0.5 and $1 \mathrm{~mm}$ and above $1 \mathrm{~mm}$ were higher in Groups 1 and 2, in distinct areas marked by lighter blue, green and red colours on one participant's foot from each group. These are: the toes, the ankle, the dorsal surface, the lateral edge of the foot, under the ball of the foot and the lateral part of the plantar surface.
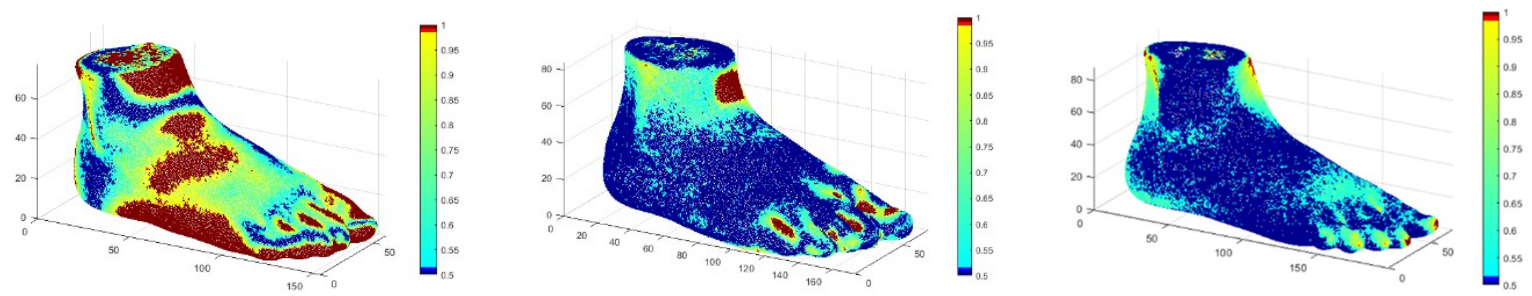

Figure 5: Mesh deviation heat maps for one participant's foot from each group (left: Group 1: Participant 1, middle: Group 2: Participant 1, right: Group 3: Participant 3), deviations increasing from blue to red, dark blue:0.5mm or less deviation, light blue through green and yellow deviations between 0.5 and $1 \mathrm{~mm}$ and red meaning deviations $1 \mathrm{~mm}$ or above, lateral view. 

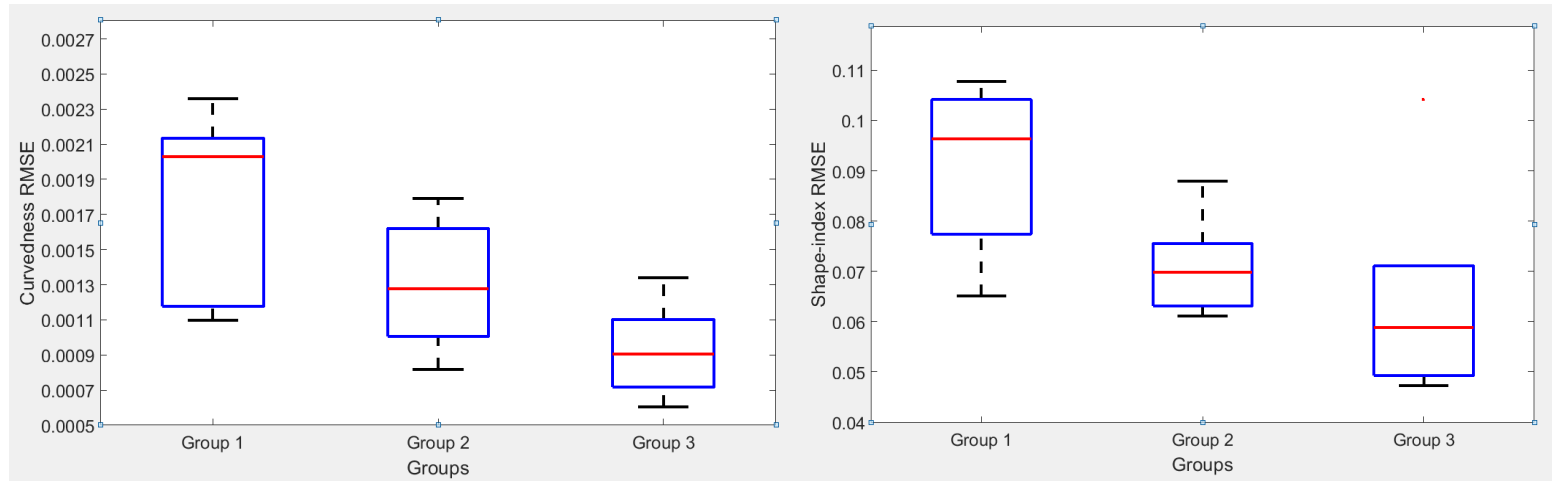

Figure 6: Curvedness (left) and shape-index (right) RMSE boxplot for each group.

Curvedness and shape-index RMSE for each group are shown in Figure 6. The figures show that both the curvedness and shape-index RMSE decreases with age. Figures 8 and 9 show the RMSE heat maps of curvedness and shape-index respectively for one participant from each group. The curvedness and shape-index root mean square errors show a similar tendency to the mesh deviations, but with less differences between the groups. Most differences in reliability were found around the toes, the lateral and dorsal surface and the heel.
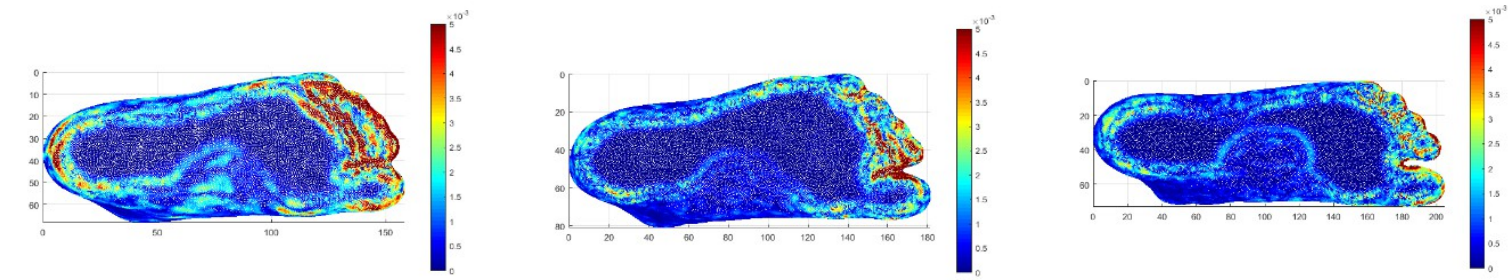

Figure 8: Curvedness RMSE heat maps for an example foot from each age group (top: Group 1: Participant 1, middle: Group 2: Participant 1, bottom: Group 3: Participant 3), RMSE increasing from blue to red, plantar view.
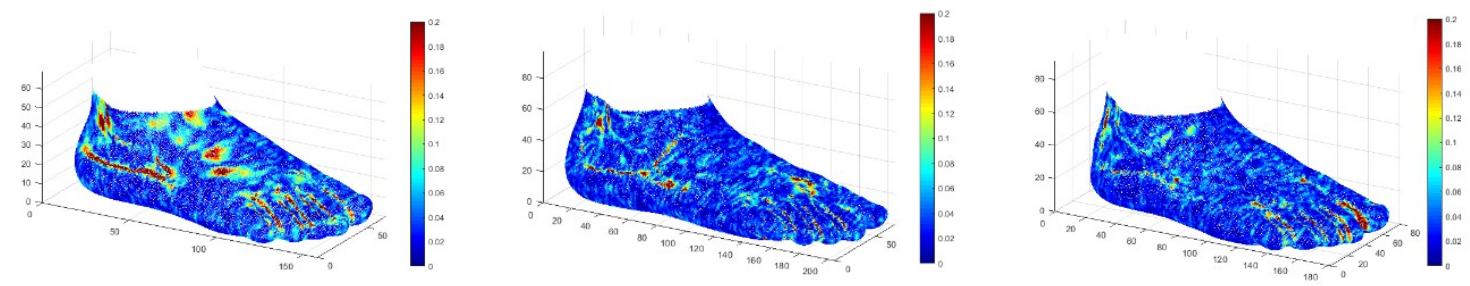

Figure 9: Shape-index RMSE heat maps for an example foot from each group (top: Group 1: Participant 1, middle: Group 2: Participant 1, bottom: Group 3: Participant 3), RMSE increasing from blue to red, lateral view.

\section{Discussion}

The reliability of using a hand held 3D scanner to measure children's foot shape and size between the ages of two and seven years was investigated in 15 children. The results showed good reliability in the older children (Groups 2 and 3). Group 1 had higher RMSE values in two linear measures compared to the literature. The higher 3D measure RMSEs compared to the other two groups also suggest poorer reliability of the methods used in this group.

\subsection{Reliability of linear measurements}

Linear measurements showed excellent reliability in Groups 2 and 3, but not in Group 1. In comparison to existing data from Mauch, Grau [42], the results from Group 1 have demonstrated greater values of RMSE in two linear measures: MTH1 and MTH5 length. Although these two anatomical landmarks (MTH1 and MTH5) are relatively easy to locate, it seems that the location of these, relative to the most posterior aspect of the calcaneus changed between scans more than it did in the other groups. This could suggest variation in angle of stance between scans resulting in changing foot shape for this group. The higher absolute RMSE in most of the other linear measures in this group supports this argument. Another possible reason for this finding is the software that was used to calculate the measures (Foot3D) as the algorithms were developed from adult feet, and hence there were discrepancies with the location of the anatomical landmarks. Due to these findings on-going work will utilise bespoke Matlab code using markers attached to the anatomical landmarks. 


\subsection{Reliability of 3D shape measurement}

The reliability of 3D foot shape measurement was evaluated using mesh deviations; and calculating absolute RMSE of 3D shape descriptors. Group 1 had considerably lower percentage of vertex deviations under 0.5 and $1 \mathrm{~mm}$. The heat maps (Figures 5) showing the deviations on the foot surface help to locate the areas with higher variation and can suggest possible causes for these findings. The higher deviations in the toes area in Group 1 and 2 indicate that there was greater movement between the scans for the younger children. Group 1 also demonstrated larger areas of mesh deviations over $1 \mathrm{~mm}$ (red) around the ankle, on the lateral surface of the sole and under the metatarsals, and on the dorsal surface. This is also consistent with the difficulties that were encountered during data collection: movement during scanning; and differences in stance between scans witnessed by the researcher. The reliability of the 3D shape descriptors represented by the absolute RMSE increased with age and was the highest in Group 3. The differences in reliability were clear around the toes, the ankle and the dorsal surface of the foot.

\section{Conclusion}

Based on the results, it can be concluded, that hand-held 3D scanning was reliable for capturing linear and three dimensional shape measures in children aged five and seven years. Future studies employing hand held 3D scanners should consider these results and consider the use of this technology in younger children with caution. The 3D shape descriptor RMSE values in Group 2 and 3 suggest that these measures can be used to complement 2D linear measures to quantify changes in foot shape during development. Shape-index and curvedness can help to describe 3D shape changes, where 2D measures cannot fully account for development occurring in the paediatric foot.

\section{References}

[1] Gilmour, J.C. and Y. Burns, The measurement of the medial longitudinal arch in children. Foot \& Ankle International, 2001. 22(6): p. 493-498.

[2] Kouchi, M., Foot Dimensions and Foot Shape: Differences Due to Growth, Generation and Ethnic Origin. Anthropological Science, 1998. 106(Supplement): p. 161-188.

[3] Muller, S., et al., Static and dynamic foot characteristics in children aged 1-13 years: A crosssectional study. Gait \& Posture, 2012. 35(3): p. 389-394.

[4] Waseda, A., et al., Standard growth of the foot arch in childhood and adolescence--derived from the measurement results of 10,155 children. Foot Ankle Surg, 2014. 20(3): p. 208-14.

[5] Forriol, F., et al., Footprint analysis between three and seventeen years of age. Foot and Ankle, 1990. 11(2): p. 101-104.

[6] Chang, H.W., et al., Three-dimensional measurement of foot arch in preschool children. Biomedical Engineering Online, 2012. 11.

[7] Aboelnasr, E.A., et al., Validation of normalized truncated navicular height as a clinical assessment measure of static foot posture to determine flatfoot in children and adolescents: $A$ cross sectional study. The Foot, 2018. 37: p. 85-90.

[8] Banwell, H.A., et al., Paediatric flexible flat foot: how are we measuring it and are we getting it right? A systematic review. Journal of Foot and Ankle Research, 2018. 11(1): p. 21.

[9] Ganesan, B., et al., Developing a Three-Dimensional (3D) Assessment Method for Clubfoot-A Study Protocol. Frontiers in Physiology, 2018. 8(1098).

[10] Mauch, M., et al., A new approach to children's footwear based on foot type classification. Ergonomics, 2009. 52(8): p. 999-1008.

[11] Ding, Y., et al., An automatic method of measuring foot girths for custom footwear using local RBF implicit surfaces. International Journal of Computer Integrated Manufacturing, 2010. 23(6): p. 574-583.

[12] Hill, M., et al., The relationship between arch height and foot length: Implications for size grading. Applied Ergonomics, 2017. 59: p. 243-250.

[13] Klein, C., et al., Increased hallux angle in children and its association with insufficient length of footwear: A community based cross-sectional study. BMC Musculoskeletal Disorders, 2009. 10(1): p. 159.

[14] Price, C. and C. Nester, Foot dimensions and morphology in healthy weight, overweight and obese males. Clinical Biomechanics, 2016. 37: p. 125-130.

[15] Telfer, S. and J. Woodburn, The use of $3 D$ surface scanning for the measurement and assessment of the human foot. Journal of Foot and Ankle Research, 2010. 3. 
[16] Lee, Y.C. and M.J. Wang, Taiwanese adult foot shape classification using 3D scanning data. Ergonomics, 2015. 58(3): p. 513-523.

[17] Tsung, B.Y.S., et al., Quantitative comparison of plantar foot shapes under different weightbearing conditions. Journal of Rehabilitation Research and Development, 2003. 40(6): p. 517526.

[18] Xiong, S.P., et al., Foot deformations under different load-bearing conditions and their relationships to stature and body weight. Anthropological Science, 2009. 117(2): p. 77-88.

[19] Jimenez-Ormeno, E., et al., Foot morphology in normal-weight, overweight, and obese schoolchildren. European Journal of Pediatrics, 2013. 172(5): p. 645-652.

[20] Mauch, M., et al., Foot morphology of normal, underweight and overweight children. International Journal of Obesity, 2008. 32(7): p. 1068-1075.

[21] Houston, V.L., et al., Changes in male foot shape and size with weightbearing. Journal of the American Podiatric Medical Association, 2006. 96(4): p. 330-343.

[22] Uden, H., R. Scharfbillig, and R. Causby, The typically developing paediatric foot: how flat should it be? A systematic review. Journal of Foot and Ankle Research, 2017. 10.

[23] Liu, X., W. Kim, and B. Drerup, 3D characterization and localization of anatomical landmarks of the foot by FastSCAN. Real-Time Imaging, 2004. 10(4): p. 217-228.

[24] Bland, J.M. and D.G. Altman, Statistics notes: Measurement error. BMJ, 1996. 312(7047): p. 1654.

[25] T. Allard, T., et al., Use of Hand-held Laser Scanning and 3D Printing for Creation of a Museum Exhibit. 2005.

[26] Hebal, F., et al., A novel technique to measure severity of pediatric pectus excavatum using white light scanning. Journal of Pediatric Surgery, 2019. 54(4): p. 656-662.

[27] Port, E., et al., Measuring the impact of surgical intervention on pediatric pectus excavatum using white light scanning. Journal of Pediatric Surgery, 2019.

[28] Armitage, L., L.K. Kwah, and L. Kark, Reliability and validity of the iSense optical scanner for measuring volume of transtibial residual limb models. Prosthetics and Orthotics International, 2019. 43(2): p. 213-220.

[29] Park, H.-K., J.-W. Chung, and H.-S. Kho, Use of hand-held laser scanning in the assessment of craniometry. Forensic Science International, 2006. 160(2): p. 200-206.

[30] Seminati, E., et al., Validity and reliability of a novel 3D scanner for assessment of the shape and volume of amputees' residual limb models. PLoS One, 2017. 12(9): p. e0184498.

[31] Dessery, Y. and J. Pallari, Measurements agreement between low-cost and high-level handheld $3 D$ scanners to scan the knee for designing a 3D printed knee brace. PLOS ONE, 2018. 13(1): p. e0190585.

[32] Grant, C.A., et al., Accuracy of $3 D$ surface scanners for clinical torso and spinal deformity assessment. Medical Engineering \& Physics, 2019. 63: p. 63-71.

[33] Menz, H.B., Two feet, or one person? Problems associated with statistical analysis of paired data in foot and ankle medicine. The Foot, 2004. 14(1): p. 2-5.

[34] Chen, Y., et al., Object modelling by registration of multiple range images. Image Vision Comput., 1992. 10(3): p. 145-155.

[35] Besl, P.J. and N.D. McKay, A method for registration of 3-D shapes. IEEE Transactions on Pattern Analysis and Machine Intelligence, 1992. 14(2): p. 239-256.

[36] Peyre, G., Toolbox Graph. MATLAB Central File Exchange, 2007.

[37] Cohen-Steiner, D. and J.-M. Morvan, Restricted delaunay triangulations and normal cycle, in Proceedings of the nineteenth annual symposium on Computational geometry. 2003, ACM: San Diego, California, USA. p. 312-321.

[38] Alliez, P., et al., Anisotropic polygonal remeshing, in ACM SIGGRAPH 2003 Papers. 2003, ACM: San Diego, California. p. 485-493.

[39] Koenderink, J.J. and A.J. van Doorn, Surface shape and curvature scales. Image and Vision Computing, 1992. 10(8): p. 557-564.

[40] O'Meara, D., et al., The reliability and validity of a three-camera foot image system for obtaining foot anthropometrics. Journal of Applied Biomechanics, 2010. 26(3): p. 349-356.

[41] Wan, F.K.W., K.-L. Yick, and W.W.M. Yu, Validation of a 3D foot scanning system for evaluation of forefoot shape with elevated heels. Measurement, 2017. 99: p. 134-144.

[42] Mauch, M., et al., Foot morphology of normal, underweight and overweight children. Int J Obes (Lond), 2008. 32. 